\title{
Avaliação de Fontes de Urease na Amonização de Fenos de Brachiaria brizantha com Dois Teores de Umidade
}

\section{Liandra Maria Abaker Bertipaglia1, Silvio De Luca², Gabriel Maurício Peruca de Melo³, Ricardo Andrade Reis ${ }^{4}$}

\begin{abstract}
RESUMO - O efeito da amonização com uréia (5,0\% matéria seca) do feno de Brachiaria brizantha, com dois teores de umidade (15 ou $30 \%$ de umidade), associado a três fontes de urease (feno de capim Brachiaria decumbens, capim-elefante [Pennisetum purpureum] e leucena [Leucaena leucocephala]), foi avaliado. Foram determinados os teores de proteína bruta (PB), fração solúvel (A), frações de proteína verdadeira solúvel e insolúvel em borato fosfato (B1 e B2), fração de proteína potencialmente degradável (B3) e fração da proteína insolúvel em detergente ácido (C). Avaliaram-se os teores de fibra em detergente neutro (FDN), fibra em detergente ácido (FDA), celulose (CEL), hemicelulose (HEM) e lignina (LIG) e digestibilidade in vitro da matéria seca (DIVMS). O delineamento experimental foi o de blocos inteiramente casualizados, com 10 tratamentos (dois controles, 15 e 30\% umidade, sem uréia e sem urease; dois controles, 15 e 30\% umidade, com uréia e sem urease; seis combinações de fontes de urease e conteúdo de umidade) e três repetições. A amonização dos fenos com diferentes conteúdos de umidade, associados a fontes de urease, aumentou os teores de PB e da fração A, mas não afetou B1 e B2. Contudo, as frações B3 e C diminuíram em reposta à amonização. A aplicação de uréia nos fenos de 30\% de umidade, associados ou não a fontes de urease, diminuiu os teores de FDN. A adição de fontes de urease não alterou os teores dos constituintes da parede celular, quando comparada aos tratamentos amonizados com uréia. Os tratamentos aplicados não proporcionaram efeitos consistentes sobre os teores de FDA e de CEL dos fenos e não afetaram os teores de LIG. A aplicação de uréia associada a 15 ou $30 \%$ de umidade foi favorável para aumentar o nitrogênio solúvel do feno de Brachiaria brizantha e diminuir o nitrogênio indisponível para o ruminante.
\end{abstract}

Palavras-chave: Brachiaria decumbens, capim-elefante, leucena, tratamento químico

\section{Evaluation of Urease Sources in the Ammoniation of Brachiaria brizantha Hays with Two Moisture Levels}

\begin{abstract}
The urea ammoniation (5.0\% dry matter) effects in Brachiaria brizanta hay baled with two moisture contents (15 or $30 \%$ moisture), and three urease source (Brachiaria decumbens hay, elephantgrass (Pennisetum purpureum), leucena (Leucaena leucocephala)) was evaluated. The crude protein (CP), soluble nitrogen fraction (A), borate phosphate true protein fractions (B1 and B2), potentially degradable protein fraction (B3), acid detergent insoluble protein (C) were analyzed. The NDF, ADF, cellulose, hemicellulose and lignin contents and in vitro dry matter digestibility (IVDMD) were analyzed. The experiment was conducted according to a completely randomized block design with 10 treatments (two control, 15 and 30\% moisture, without urea and urease; two controls, 15 and 30\% moisture, with urea and urease; six combinations of urease source and moisture levels), with three replicates. Ammoniation increased $\mathrm{CP}$, and $\mathrm{A}$ fractions of the hays baled with different moisture contents associated to urease source; however urea application did not affect the B1, and B2 values. The B3 and C values decreased due to the urea application. The ammoniation of the high moisture hay $(30 \%)$, associated or not to urease source reduced NDF. External urease source did not affect the cell wall contents of the brachiaria hay, compared to the urea treatment without external urease. Ammoniation with urea had a unconsistent effect on the ADF, and cellulose contents of the hay. The treatment did not affect the lignin content of the hay. The urea application with 15 or $30 \%$ moisture increased soluble nitrogen of Brachiaria brizantha hay and decreased the unavailable nitrogen to the ruminant.
\end{abstract}

Key Words: Brachiaria decumbens, chemical treatment, elephantgrass, leucena

\section{Introdução}

As alterações quantitativas e qualitativas observadas no período de restrições climáticas, para as forrageiras de clima tropical, resultam na necessidade de se produzir forragem suplementar de alto valor nutritivo. É fato que a forragem disponível nas pastagens durante o período seco não contém todos os nutrientes essenciais, na proporção adequada, de forma a atender integralmente às exigências dos animais em pastejo.

\footnotetext{
1 Zootecnista, aluna de doutorado no programa de pós-graduação em Zootecnia, FCAV-UNESP campus de Jaboticabal (liandramab@terra.com.br).

2 Zootecnista, pela FCAV-UNESP campus de Jaboticabal.

3 Zootecnista, Doutor pela FCAV-UNESP campus de Jaboticabal (gmpmelo@terra.com.br).

4 Docente do Departamento de Zootecnia, FCAV-UNESP campus de Jaboticabal, pesquisador CNPq (rareis@fcav.unesp.br).
} 
Contudo, os custos de produção de volumosos conservados, na forma de silagem ou de feno, bem como as dificuldades relacionadas ao clima, podem inviabilizar a adoção dessas técnicas.

A utilização de volumosos de baixo valor nutritivo submetidos aos tratamentos físicos, químicos ou biológicos pode ser uma alternativa apropriada para se fornecer forragem de qualidade, atendendo ao requerimento nutricional dos bovinos e amenizando os efeitos da estacionalidade da produção de forragem de alta qualidade (Reis et al., 2001).

Os tratamentos com produtos oxidantes ou com compostos hidrolíticos podem ser usados para melhorar o valor nutritivo desses volumosos, destacando-se a amônia anidra $\left(\mathrm{NH}_{3}\right)$ e a uréia como fonte de amônia (Dolberg, 1991).

A adição de fonte de urease pode aumentar a eficiência da amonização de volumosos via hidrólise da uréia, pois as reduções da quantidade de água para aplicação do produto químico e do tempo de tratamento, segundo Sahnoune et al. (1991), são vantajosas.

Este estudo foi conduzido com o objetivo de se determinar a influência do teor de umidade e de diferentes fontes de urease sobre os teores dos compostos nitrogenados e dos componentes da parede celular do feno de Brachiaria brizantha submetido a amonização via aplicação da uréia.

\section{Material e Métodos}

O experimento foi conduzido na Faculdade de Ciências Agrárias e Veterinárias UNESP, campus de Jaboticabal, para se determinar os efeitos da amonização com uréia (5\% da matéria seca), da adição de fontes de urease e do teor de umidade sobre a composição química do feno de Brachiaria brizantha colhida no estádio de pós-florescimento. O volumoso avaliado foi proveniente de áreas da Estação Experimental de Sertãozinho, Instituto de Zootecnia do Estado de São Paulo. A fenação da Brachiaria brizantha foi realizada após a colheita das sementes, obtendo-se um material de baixa qualidade.

Foram avaliados os seguintes tratamentos: feno de Brachiaria brizantha com 15\% de umidade, $2 \%$ de feno Brachiaria decumbens e $5 \%$ de uréia; feno de Brachiaria brizantha com $15 \%$ de umidade, $2 \%$ de capim-elefante (Peninsetum purpureum) e 5\% de uréia; feno de Brachiaria brizantha com $15 \%$ de umidade, $2 \%$ de leucena (Leucaena leucocephala) e 5\% de uréia; feno de Brachiaria brizantha com $15 \%$ de umidade, sem fonte de urease e $5 \%$ de uréia; feno de Brachiaria brizantha com $15 \%$ de umidade, sem fonte de urease e sem uréia; feno de Brachiaria brizantha com $30 \%$ de umidade, $2 \%$ de feno Brachiaria decumbens e $5 \%$ de uréia; feno de Brachiaria brizantha com $30 \%$ de umidade, $2 \%$ de capim-elefante e $5 \%$ de uréia; feno de Brachiaria brizantha com $30 \%$ de umidade, $2 \%$ de leucena e $5 \%$ de uréia; feno de Brachiaria brizantha com $30 \%$ de umidade, sem fonte de urease e $5 \%$ de uréia; e feno de Brachiaria brizantha com $30 \%$ de umidade, sem fonte de urease e sem uréia.

Para cada tratamento formou-se uma pilha de nove fardos (65 kg de MS) de feno de Brachiaria brizantha, dispostos em três camadas (com três fardos cada), constituindo, deste modo, três blocos. Adotou-se a posição dos fardos como blocos, pois, segundo Joy et al. (1992), há maior variação na distribuição da amônia dentro da pilha, em razão da proximidade da lona e altura dos fardos, do que entre as pilhas.

A escolha das fontes de urease utilizadas baseouse na atividade ureática determinada de acordo com Hogan et al. (1983). As forrageiras utilizadas como fonte de urease foram picadas em pedaços de, aproximadamente, $2 \mathrm{~cm}$. A leucena foi adicionada usando os ramos com $0,5 \mathrm{~cm}$ de diâmetro, contendo folhas colhidas na porção inferior da planta e com atividade da urease de $1.122,38 \mathrm{mg} \mathrm{NH}_{3} / \mathrm{kg} / \mathrm{h}$ na MS. O capimelefante foi colhido no estádio reprodutivo (aproximadamente 1,5 $\mathrm{m}$ de altura), usando-se a parte aérea (caule e folha) da planta, com atividade da urease de $627,01 \mathrm{mg} \mathrm{NH} / \mathrm{kg} / \mathrm{h}$ na MS. O feno de Brachiaria decumbens, colhida no estádio de florescimento, apresentou atividade ureolítica de $549,95 \mathrm{mg} \mathrm{NH}_{3} / \mathrm{kg} / \mathrm{h}$ na MS e o feno de Brachiaria brizantha, colhida no estádio de pós-florescimento, de 346,5295 mg NH $3 / \mathrm{kg} / \mathrm{h}$ na MS.

$\mathrm{Na}$ confecção das pilhas de fardos de feno, estendeu-se uma lona plástica preta sobre o solo, sobre a qual foi colocado um estrado de madeira, obtendo-se os nove fardos dispostos em três camadas (blocos). Nos tratamentos com adição de fontes de urease, determinou-se a quantidade a ser aplicada tomandose o peso total da pilha e multiplicando-se por 0,02 . Esta quantidade foi dividida em quatro porções, sendo uma aplicada sobre o estrado e as demais distribuídas, conforme a montagem da pilha, sobre as camadas dos fardos de feno.

$\mathrm{O}$ ajuste do teor de umidade dos fardos foi feito com adição de água, aplicada por aspersão com auxílio de regador na quantidade calculada, para se elevar 
o conteúdo de umidade para 15 ou $30 \%$. A quantidade de água foi obtida tomando-se o peso total da pilha e o teor de matéria seca dos fardos de feno. A seguir, dividiu-se o peso da pilha (MS) pelo teor de MS desejado, multiplicou-se pela matéria seca original, obtendo-se o peso das pilhas após a adição da água.

Nos tratamentos com adição de uréia, a quantidade a ser aplicada (5\% da MS) foi diluída na água utilizada para ajustar o teor de umidade das pilhas de fardos de feno, distribuída com auxílio de um regador, uniformemente, nas três camadas.

Após o período de tratamento (60 dias), as pilhas de fardos foram abertas e, após três dias de aeração, foram tomadas 18 amostras por pilha, ou seja, seis subamostras por camada, duas para cada fardo, compondo uma amostra composta de cada bloco, com o cuidado de não coletar partes das forrageiras utilizadas como fonte de urease.

As determinações químicas foram processadas a partir das avaliações dos conteúdos de proteína bruta $(\mathrm{PB})$, proteína insolúvel em detergente neutro (PIDN) e em detergente ácido (PIDA), fibra em detergente neutro (FDN), fibra em detergente ácido (FDA) e lignina (LIG), obtendo-se os teores de hemicelulose (HEM) e celulose (CEL) segundo Silva \& Queiroz (2002). As determinações do nitrogênio não-protéico e proteína bruta insolúvel seguiram recomendações de Pereira \& Rossi (1994). A digestibilidade in vitro da matéria seca (DIVMS) foi determinada por intermédio da metodologia de Tilley e Terry, conforme Silva \& Queiroz (2002).

$\mathrm{O}$ experimento foi conduzido de acordo com o delineamento em blocos inteiramente casualizados, composto por 10 tratamentos, com três repetições (camadas nas pilhas de fardos de feno que constituíram os três blocos). As médias foram comparadas pelo teste Tukey, a 5\% de probabilidade.

\section{Resultados e Discussão}

Observou-se aumento $(\mathrm{P}<0,05)$ nos teores de $\mathrm{PB}$ (Tabela 1) dos fenos tratados com uréia, independentemente das fontes de urease e dos conteúdos de umidade avaliados. Observa-se que os maiores teores de PB foram registrados nos fenos de Brachiaria brizantha com $15 \%$ de umidade e tratados com uréia. Resultados semelhantes foram observados por Reis et al. (2001) e por Rosa et al. (1998), em estudos sobre a amonização de fenos de gramíneas tropicais utilizando uréia. De acordo com Schmidt et al. (2003), a elevação do teor de PB no feno amonizado pode estar ligada à retenção de nitrogênio, e esta, à atividade ureolítica responsável pela transformação da uréia em amônia, sendo que a retenção de nitrogênio com o tratamento de feno de Brachiaria decumbens com $25 \%$ de umidade, amonizado com 5\% de uréia (MS), observada por aqueles autores foi de $76 \%$.

É importante salientar que os fenos tratados com uréia, exceto aquele com $30 \%$ de umidade e tratado com capim-elefante e uréia, apresentaram maiores valores da fração $\mathrm{A}$, correspondente ao conteúdo de nitrogênio não-protéico, comparado aos não-tratados (Tabela 1). Segundo Berger et al. (1994), a principal forma de retenção do nitrogênio, via uréia, no processo de amonização é a de nitrogênio não-protéico, ou seja, a fração de $\mathrm{N}$ solúvel da forragem.

Houve efeito $(\mathrm{P}<0,05)$ dos conteúdos de umidade e das fontes de urease avaliadas sobre as frações B1 e B2 (Tabela 1), ressaltando-se que, nos tratamentos em que o efeito da uréia e das fontes de urease foi mais expressivo em elevar a fração A, ocorreu diminuição da B1 e B2, além de provável efeito de diluição. Contudo, inferese que a fração B2 apresentou maior participação, quando relacionada à $\mathrm{PB}$, comparada à fração $\mathrm{B} 1$ (Tabela 1 ). Constata-se que a aplicação de uréia tem pequena participação nas frações B1 e B2, pois refere-se à proteína verdadeira da forragem (Pereira \& Rossi, 1994).

A análise dos dados relacionados à fração B3 evidencia maiores valores $(\mathrm{P}<0,05)$ para os fenos não-tratados, em comparação aos tratados com uréia. A hidrólise dos componentes da fração fibrosa, principalmente da FDN (Tabela 2), pode explicar o menor conteúdo de nitrogênio potencialmente degradável, pois com o tratamento tem-se aumento na fração de $\mathrm{N}$ solúvel (Tabela 1). Estes resultados confirmam os obtidos por Reis et al. (2001) e por Rosa et al. (1998), ao avaliarem os efeitos aplicação de uréia sobre os conteúdos de compostos nitrogenados de fenos de gramíneas forrageiras tropicais.

Os teores de proteína insolúvel em detergente ácido (PIDA), correspondentes à fração $\mathrm{C}$, foram influenciados pelos tratamentos estudados $(\mathrm{P}<0,05)$. Maiores valores foram observados para os fenos nãotratados, comparados aos que receberam uréia. $\mathrm{Na}$ literatura, são reportados efeitos contraditórios a respeito dos efeitos da amonização sobre esse parâmetro. Rosa et al. (1998) relataram aumentos dos teores de NIDA para os fenos, ao passo que Martins (1992) e Reis et al. (1993) não observaram alterações significativas nessa fração. 
Tabela 1 - Frações da proteína de feno de Brachiaria brizantha, tratado ou não com uréia e com a adição ou não de fontes de urease

Table 1 - Protein fraction evaluated on Brachiaria brizantha, treated or not with urea and additioned or not with external urease source

\begin{tabular}{lcccccc}
\hline Tratamento & $\mathrm{PB}(\% \mathrm{MS})$ & $\mathrm{A}(\% \mathrm{~PB})$ & $\mathrm{B} 1(\% \mathrm{~PB})$ & $\mathrm{B} 2(\% \mathrm{~PB})$ & $\mathrm{B} 3(\% \mathrm{~PB})$ & $\mathrm{C}(\% \mathrm{~PB})$ \\
Treatment & $C P(\% D M)$ & $A(\% C P)$ & $B 1(\% C P)$ & $B 2(\% C P)$ & $B 3(\% C P)$ & $C(\% C P)$ \\
\hline $\begin{array}{l}\text { Feno } 15 \% \text { umidade } \\
\text { sem uréia }\end{array}$ & $3,09^{\mathrm{D}}$ & $49,09^{\mathrm{E}}$ & $0,1473^{\mathrm{BC}}$ & $19,18^{\mathrm{A}}$ & $5,87^{\mathrm{A}}$ & $25,70^{\mathrm{A}}$ \\
& & & & & &
\end{tabular}

Hay $15 \%$ moisture

without urea

Feno $15 \%$ umidade $\quad 16,31^{\mathrm{A}} \quad 85,72^{\mathrm{AB}} \quad 0,0473^{\mathrm{B}} \quad 8,75^{\mathrm{CDE}} \quad 0,99^{\mathrm{B}} \quad 4,47^{\mathrm{B}}$

+ uréia

Hay $15 \%$ moisture

+ urea

Feno $15 \%$ umidade

+ B.decumbens

+ uréia

Hay $15 \%$ moisture

+ B. decumbens

+ urea

Feno $15 \%$ umidade

+ Capim-elefante

+ uréia

Hay $15 \%$ moisture

+ Elephantgrass + urea

Feno 15\% umidade

$$
12,42^{\mathrm{ABC}} \quad 76,22^{\mathrm{BC}}
$$

$0,1570^{\mathrm{BC}}$

$15,38^{\mathrm{ABC}}$

$1,48^{\mathrm{B}}$

$6,73^{\mathrm{B}}$

+ Leucena + uréia

Hay $15 \%$ moisture

+ Leucena + urea

Feno 30\% umidade sem uréia

Hay $30 \%$ moisture without urea

Feno 30\% umidade

+ uréia

Hay 30\% moisture + urea

Feno 30\% umidade

$10,59^{\mathrm{BC}}$

$76,17^{\mathrm{BC}}$

$0,1373^{\mathrm{BC}}$

$14,09^{\mathrm{ABCD}}$

$1,03^{\mathrm{B}}$

$8,56^{\mathrm{B}}$

+ B.decumbens

+ uréia

Hay 30\% moisture

+ B. decumbens + urea

Feno $30 \%$ umidade +

Capim-elefante + uréia

Hay 30\% moisture

+ Elephantgrass + urea

Feno $30 \%$ umidade

$11,04^{\mathrm{BC}}$

$77,81^{\mathrm{ABC}} 0,3723^{\mathrm{B}}$

$12,08^{\mathrm{BCDE}}$

$1,15^{\mathrm{B}}$

$8,57^{\mathrm{B}}$

+ Leucena + uréia

Hay 30\% moisture

+ Leucena + urea

Média

10,59

75,04

0,24

11,74

2,23

10,99

$\mathrm{CV}(\%)$

14,81

4,45 35,99

19,35

46,70

18,08

Médias seguidas de letras distintas nas colunas diferem $(P<0,05)$ pelo teste Tukey.

Means followed by the different letters in the column are different $(P<.05)$ by Tukey test. 
Tabela 2 - Teores de fibra em detergente neutro (FDN), fibra em detergente ácido (FDA), hemicelulose (HEM), celulose (CEL) e lignina (LIG) do feno de Brachiaria brizantha tratado ou não com uréia e fontes de urease

Table 2 - Neutral detergent fiber (NDF), acid detergent fiber (ADF), hemicellulose (HEM), cellulose (CEL) and lign (LIG) values evaluated on Brachiaria brizantha, treated or not with urea and urease source

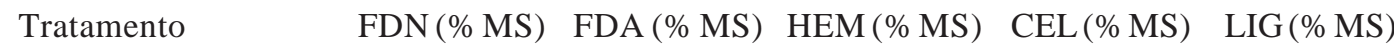

\begin{tabular}{lccccc} 
Treatment & $N D F(\% D M)$ & $A D F(\% D M)$ & $H E M(\% D M)$ & $C E L(\% D M)$ & $L I G(\% D M)$ \\
\hline Feno $15 \%$ umidade & $77,49^{\mathrm{AB}}$ & $42,23^{\mathrm{A}}$ & $35,26^{\mathrm{AB}}$ & $35,83^{\mathrm{AB}}$ & $6,37^{\mathrm{A}}$
\end{tabular}

sem uréia

Hay $15 \%$ moisture

without urea

Feno $15 \%$ umidade

$69,79^{\mathrm{F}}$

$37,67^{\mathrm{B}}$

$32,13^{\mathrm{ABCD}}$

$32,71^{\mathrm{B}}$

$4,96^{\mathrm{A}}$

+ uréia

Hay $15 \%$ moisture + urea

Feno $15 \%$ umidade

$73,32^{\mathrm{CDE}}$

$40,61^{\mathrm{AB}}$

$32,70^{\mathrm{ABCD}}$

$39,19^{\mathrm{AB}}$

$5,42^{\mathrm{A}}$

+ B.decumbens

+ uréia

Hay $15 \%$ moisture

+ B. decumbens + urea

Feno $15 \%$ umidade

+Capim-elefante

$75,00^{\mathrm{BCD}}$

$40,98^{\mathrm{AB}}$

$34,01^{\mathrm{ABC}}$

$34,76^{\mathrm{AB}}$

$6,23^{\mathrm{A}}$

+ uréia

Hay $15 \%$ moisture

+ Elephantgrass

+ urea

Feno $15 \%$ umidade

+ Leucena + uréia

$76,56^{\mathrm{ABC}}$

$41,13^{\mathrm{A}}$

$35,42^{\mathrm{AB}}$

$35,10^{\mathrm{AB}}$

$6,04^{\mathrm{A}}$

Hay $15 \%$ moisture

+ Leucena + urea

Feno $30 \%$ umidade

sem uréia

$78,75^{\mathrm{A}}$

$42,59^{\mathrm{A}}$

$36,16^{\mathrm{A}}$

$36,23^{\mathrm{A}}$

$6,37^{\mathrm{A}}$

Hay 30\% moisture

without urea

Feno 30\% umidade

+ uréia

Hay $30 \%$ moisture + urea

Feno $30 \%$ umidade

+ B.decumbens

+ uréia

Hay 30\% moisture

+ B. decumbens + urea

Feno 30\% umidade

+ Capim-elefante

$$
71,10^{\mathrm{EF}}
$$

$42,31^{\mathrm{A}}$

$28,79^{\mathrm{D}}$

$36,27^{\mathrm{A}}$

$6,08^{\mathrm{A}}$

+ uréia

Hay 30\% moisture

+ Elephantgrass

+ urea

Feno $30 \%$ umidade

+ Leucena + uréia

Hay 30\% moisture

+ Leucena + urea

\begin{tabular}{|c|c|c|c|c|c|}
\hline $\begin{array}{l}\text { Feno } 30 \% \text { umidade } \\
\text { + Leucena + uréia } \\
\text { Hay 30\% moisture } \\
+ \text { Leucena + urea }\end{array}$ & $70,73^{\mathrm{EF}}$ & $40,43^{\mathrm{AB}}$ & $30,29^{C D}$ & $34,84^{\mathrm{AB}}$ & $5,59^{\mathrm{A}}$ \\
\hline Média & 73,96 & 40,97 & 33,00 & 35,09 & 5,87 \\
\hline $\begin{array}{l}\text { Mean } \\
\text { CV }(\%)\end{array}$ & 1,62 & 2,83 & 4,20 & 3,16 & 9,00 \\
\hline
\end{tabular}

Médias seguidas de letras distintas nas colunas diferem $(P<0,05)$ pelo teste Tukey.

Means followed by the different letters in the column are different $(P<.05)$ by Tukey test. 
É importante salientar que a fração $C$ representa a porção do nitrogênio indisponível para os microrganismos do rúmen e, dessa forma, sua diminuição na forragem é de suma importância para melhoria da qualidade nutricional dos volumosos de baixo valor nutritivo (Reis et al., 2001). De maneira geral, as principais alterações nos conteúdos de compostos nitrogenados dos volumosos submetidos à amonização referem-se ao aumento nos teores de nitrogênio total (NT), de nitrogênio solúvel e da fração insolúvel em detergente ácido (Reis et al., 1990).

Observou-se efeito dos tratamentos (Tabela 2) sobre os teores de FDN $(\mathrm{P}<0,05)$, com o menor valor para o tratamento com $15 \%$ de umidade, tratado com $5 \%$ de uréia, sem fonte de urease, o qual não diferiu do tratamento com $30 \%$ de umidade, $2 \%$ de Pennisetum purpureum e 5\% de uréia, do tratamento com $30 \%$ de umidade, sem urease e $5 \%$ de uréia e do tratamento com $30 \%$ de umidade, $2 \%$ de Leucaena leucocephala e 5\% de uréia. Maiores teores foram observados nos tratamentos com $15 \%$ de umidade, $2 \%$ de Leucaena leucocephala e $5 \%$ de uréia e com $15 \%$ de umidade, sem urease e uréia e $30 \%$ de umidade, sem urease e uréia. Da mesma forma, Reis et al. (2001) observaram redução significativa na fração FDN em fenos tratados com uréia mais labe-labe em relação aos não-tratados. A avaliação das fontes de urease evidenciou que, independentemente do conteúdo de umidade dos fenos, não houve diferença nos teores de FDN e de hemicelulose $(\mathrm{P}>0,05)$, quando comparados aos tratamentos com adição somente de uréia e, em alguns casos, observou-se efeito adverso. Ressalta-se que a redução dos efeitos da amonização sobre o teor de FDN pode ter ocorrido em função da adição de material com elevado poder tampão, corroborando os dados obtidos por Bernhard et al. (1995).

A aplicação de uréia nos fenos de $30 \%$ de umidade (Tabela 2), associada ou não a fontes de urease, diminuiu $(\mathrm{P}<0,05)$ os teores de FDN e de HEM, com exceção do tratamento com Brachiaria decumbens, que, no caso da hemicelulose, não diferiu significativamente do tratamento com $30 \%$ de umidade, nãoamonizado. No entanto, deve-se ressaltar que o feno amonizado com 15 ou $30 \%$ de umidade e sem fonte de urease não diferiu estatisticamente $(\mathrm{P}<0,05)$.

Fenos com $30 \%$ de umidade, tratados com Brachiaria decumbens e 5\% de uréia, apresentaram menores conteúdos de HEM, mas não diferiram estatisticamente do tratamento com $30 \%$ de umidade sem adição de uréia.
No caso dos fenos com $15 \%$ de umidade, a aplicação de uréia reduziu a FDN somente para os tratamentos com 5\% de uréia e o tratamento com uréia e Brachiaria decumbens. As demais fontes de urease estudadas não diferiram do tratamento sem amonização. Não houve diferença estatística entre os tratamentos para a HEM.

Estudos conduzidos por Rosa et al. (1998) e por Fernandes et al. (2001), com fenos de gramíneas tropicais, evidenciaram efeitos da aplicação de uréia sobre os teores de FDN e de HEM dos fenos com conteúdo de umidade acima de $25 \%$. Contudo, Fernandes et al. (2001) destacaram que a distribuição inadequada da solução nos fardos diminuiu a eficiência do tratamento, sobretudo nas porções mais secas das pilhas de fardos. A análise dos dados do presente estudo e daqueles conduzidos com fenos de gramíneas do gênero Brachiaria (Reis et al., 2001) sugere que a atividade ureática dos fenos dessas plantas colhidas no estádio de pós-florescimento é suficiente para desdobrar a uréia aplicada, desde que os conteúdos de umidade não limitem a atividade da enzima. Os tratamentos aplicados não proporcionaram efeitos consistentes sobre os teores de FDA e de CEL dos fenos, confirmando os dados de Reis et al. (2001). Segundo Schmidt et al. (2003), a amonização com 5\% de uréia (MS) em fenos de Brachiaria decumbens com $25 \%$ de umidade elevou os teores de fibra em detergente ácido (FDA) e reduziu os de hemicelulose (HEM) e a proporção de hemicelulose na parede celular (HEM FDN). No entanto, Alfaya et al. (2002), quando compararam feno de capim-Annoni 2 (amonizado com $4 \%$ de uréia ou não), demonstraram que a amonização propiciou diminuição da fração de FDA de modo significativo, juntamente com os teores de CEL, em função do tratamento com uréia. Segundo os autores, a amonização do feno de capim-Annoni 2 não afetou os teores de FDN, HEM e LIG.

Semelhantemente ao resultado observado por Rosa et al. (1998), os tratamentos não afetaram $(\mathrm{P}>0,05)$ os teores de lignina dos fenos. Normalmente, não se observa efeito significante da amonização com $\mathrm{NH}_{3}$ sobre os teores de LIG de volumosos de baixo valor nutritivo.

Os valores da digestibilidade in vitro da matéria seca do feno de capim Brachiaria brizantha podem ser observados na Tabela 3.

Entre os tratamentos amonizados com umidade de $30 \%$, não houve diferença estatística $(P<0,05)$ para o parâmetro DIVMS, que, por sua vez, não diferiu dos tratamentos com $15 \%$ de umidade, amonizado com uréia e daqueles com adição de capim-elefante e leucena. 
Tabela 3 - Valores de digestibilidade in vitro da matéria seca das amostras de feno de capim Brachiaria brizantha, tratado ou não com uréia e fontes de urease

Table 3 - Values of in vitro dry matter digestibility of Brachiaria brizantha hay samples, treated or not with urea and urease source

\begin{tabular}{|c|c|}
\hline $\begin{array}{l}\text { Tratamento } \\
\text { Treatment }\end{array}$ & $\begin{array}{l}\text { DIVMS }(\%) \\
I V D M D(\%)\end{array}$ \\
\hline Feno $15 \%$ umidade sem uréia & $53,55^{\mathrm{B}}$ \\
\hline Hay $15 \%$ moisture without urea & \\
\hline $\begin{array}{l}\text { Feno } 15 \% \text { umidade + uréia } \\
\text { Hay } 15 \% \text { moisture + urea }\end{array}$ & $65,08^{\mathrm{A}}$ \\
\hline Feno $15 \%$ umidade+ B.decumbens + uréia & $52,28^{\mathrm{B}}$ \\
\hline $\begin{array}{l}\text { Hay } 15 \% \text { moisture }+ \text { B. decumbens }+ \text { urea } \\
\text { Feno } 15 \% \text { umidade }+ \text { Capim elefante }+ \text { uréia }\end{array}$ & $59,27^{\mathrm{AB}}$ \\
\hline $\begin{array}{l}\text { Hay } 15 \% \text { moisture + Capim elefante + urea } \\
\text { Feno } 15 \% \text { umidade + Leucena + uréia }\end{array}$ & $59,62^{\mathrm{AB}}$ \\
\hline $\begin{array}{l}\text { Hay } 15 \% \text { moisture }+ \text { Leucena }+ \text { urea } \\
\text { Feno } 30 \% \text { umidade sem uréia }\end{array}$ & $56,33^{\mathrm{B}}$ \\
\hline $\begin{array}{l}\text { Hay } 30 \% \text { moisture without urea } \\
\text { Feno } 30 \% \text { umidade + uréia }\end{array}$ & $66,52^{\mathrm{A}}$ \\
\hline $\begin{array}{l}\text { Hay } 30 \% \text { moisture }+ \text { urea } \\
\text { Feno } 30 \% \text { umidade }+ \text { B.decumbens }+ \text { uréia } \\
\text { Hay } 30 \% \text { moisture }+ \text { B. decumbens }+ \text { urea }\end{array}$ & $66,44^{\mathrm{A}}$ \\
\hline $\begin{array}{l}\text { Hay } 30 \% \text { molsture }+ \text { B. decumbens }+ \text { urea } \\
\text { Feno } 30 \% \text { umidade }+ \text { Capim elefante }+ \text { uréia }\end{array}$ & $64,47^{\mathrm{A}}$ \\
\hline $\begin{array}{l}\text { Hay } 30 \% \text { moisture + Elephant grass + urea } \\
\text { Feno } 30 \% \text { umidade + Leucena + uréia } \\
\text { Hay } 30 \% \text { moisture + Leucena + urea }\end{array}$ & $66,99^{\mathrm{A}}$ \\
\hline $\begin{array}{l}\text { Hay } 30 \% \text { moisture + Leucena }+ \text { urea } \\
\text { Média } \\
\text { Mean }\end{array}$ & 61,06 \\
\hline $\mathrm{CV}(\%)$ & 11,2 \\
\hline
\end{tabular}

Médias seguidas de letras distintas nas colunas diferem $(P<0,05)$ pelo teste Tukey.

Means followed by the different letters in the columns are different $(P<.05)$ by Tukey test.

Os tratamentos não-amonizados diferiram $(\mathrm{P}<0,05)$ somente dos tratamentos amonizados com $30 \%$ de umidade, independentemente da adição de fontes de urease e do tratamento amonizado com $15 \%$ de umidade, sem fonte de urease.

Para os tratamentos com $30 \%$ de umidade, a diferença entre os tratamentos amonizado e nãoamonizados foi, em média, de 10 unidades percentuais. Da mesma forma, Reis et al. (1990) observaram aumento na digestibilidade in vitro da matéria seca dos fenos de gramíneas tropicais, com adição de amônia, apresentando valores de 36,78; 49,72 e $54,33 \%$, respectivamente, para os tratamentos com 0 , 1,5 e $3 \%$ de $\mathrm{NH}_{3}$. Esta amplitude (10\%) entre os tratamentos amonizados e não-amonizados também foi observada por Nascimento (1994).

A desestruturação provocada pela amônia no arranjo dos carboidratos estruturais proporciona à microbiota do rúmen grande quantidade de substrato disponível, explicando o aumento na DIVMS dos materiais fibrosos após a amonização (Saenger et al., 1983).
Williams et al. (1984) relataram que a adição de fontes de urease não elevou a DIVMS de palha de cevada amonizada com 5\% de uréia e soja-grão (MS), como fonte de urease. Segundo esses autores, o material amonizado com uréia apresentou degradabilidade in situ da matéria seca de $47,1 \%$, enquanto o material amonizado com uréia e adição de soja-grão apresentou DIVMS de 48,2\%, não encontrando diferença significativa.

Em bagaço de cana amonizado com uréia, foi observado efeito significativo da adição de uréia sobre os valores da DIVMS, em comparação ao bagaço de cana não-tratado, sendo inferior $(23,2 \%)$ ao valor médio do bagaço amonizado $(28,5 \%)$, além de efeito linear positivo para as doses de uréia sobre a DIVMS (Cândido et al., 1999). Semelhantemente, Oji et al. (1977) observaram aumento de 8,6\% na digestibilidade de palhadas de cereais tratadas com amônia anidra, com efeito linear positivo em relação às doses de uréia adicionada.

De maneira geral, com base nos resultados obtidos, nota-se que não houve benefício da utilização de 
fonte de urease, bem como da elevação da umidade de $15 \%$ para $30 \%$, resultados contraditórios aos observados na literatura consultada.

Tomando-se como referência os valores obtidos para PB e fração A (NNP) dos tratamentos com $15 \%$ de umidade, observa-se que o tratamento com $15 \%$ de umidade, amonizados com 5\% de uréia apresentou tendência de superioridade (não-significativa estatisticamente) em relação aos tratamentos com $15 \%$ de umidade, com adição de fontes de urease. Infere-se, portanto, que ao se adicionarem fontes externas de urease ao feno de Brachiaria brizantha, que já apresentava alta atividade de urease, possivelmente pela contaminação de partículas de solo, acelerou-se a liberação de $\mathrm{NH}_{3}$ e reduziu-se sua fixação, fato que pode ser comprovado pela tendência de redução da fração A.

Nos fenos tratados com $30 \%$ de umidade, os teores de $\mathrm{PB}$ foram inferiores (não-significativo) àqueles com $15 \%$ de umidade e, da mesma forma, as fontes de urease apresentaram tendência de redução, provavelmente em função do aumento da liberação de amônia, em razão do efeito associativo da elevação da umidade e da adição de fontes de urease.

Rosa et al. (1998), avaliando a amonização de feno Brachiaria decumbens, com $3 \%$ de $\mathrm{NH}_{3}$ anidra e $5,4 \%$ de uréia, com umidade média de $15 \%$, não encontraram diferenças estatísticas entre a utilização de $3 \%$ de $\mathrm{NH}_{3}$ anidra e 5,4\% de uréia para FDN, HEM, CEL e DIVMS, sendo que o tratamento com uréia apresentou valores inferiores $(\mathrm{P}<0,05)$ para lignina e FDN, em decorrência, provavelmente, da alta atividade ureática da Brachiaria decumbens, como constatado no presente experimento.

\section{Conclusões}

O uso de 5\% de uréia na amonização propiciou condições favoráveis para o aumento do valor nutritivo do feno de Brachiaria brizantha, em relação ao material não-tratado, não havendo benefícios no uso de fontes de urease e de maior teor de umidade (de 15 para $30 \%)$.

\section{Literatura Citada}

ALFAYA, H.; SUÑÉ, L.N.P.; SIQUEIRA, C.M.G.et al. Efeito da amonização com uréia sobre os parâmetros de qualidade do feno do capim-Annoni 2 (Eragrostis plana Nees). Revista Brasileira de Zootecnia, v.31, n.2, p.842-851, 2002 (suplemento).
BERGER, L.L.; FAHEY Jr., G.C.; BOURQUIN, L.D. et al. Modification of forage quality after harvest. In: FAHEY Jr., G.C. et al. (Eds.). Forage quality evaluation, and utilization. American Society of Agronomy: Crop Science Society of America, 1994. p.922-966.

BERNHARD, E.A.; WARPECOWSKI, M.B.; CIOCCA, M.L. Caracterização de método laboratorial específico para volumosos tratados com álcalis. In: REUNIÃO ANUAL DA SOCIEDADE BRASILEIRA DE ZOOTECNIA, 32., 1995, Brasília. Anais... Brasília: Sociedade Brasileira de Zootecnia, 1995. p.209-210.

CÂNDIDO, M.J.D.; NEIVA, J.N.M.; PIMENTEL, J.C.M. et al. Avaliação do valor nutritivo do bagaço de cana-de-açúcar amonizado com uréia. Revista Brasileira de Zootecnia, v.28, n.5, p.928-935, 1999.

DOLBERG, D.F. Progress in the utilization of urea ammonia treated crop residues: Nutritional dimensions and applications of the technology on small farms. In: SIMPÓSIO INTERNACIONAL DE RUMINANTES, 1992, Lavras. Anais... Lavras: Sociedade Brasileira de Zootecnia, 1991. p.130-140.

FERNANDES, L.O.; REIS, R.A.; RODRIGUES, L.R.A. Quality evaluation of ammoniated Brachiaria decumbens hays. In: INTERNATIONAL GRASSLAND CONGRESS, 19., 2001, São Pedro. Proceedings... Piracicaba: Fundação de Estudos Agrários Luiz de Queiroz, 2001. p.779-780.

HOGAN, M.E.; SWIFT, I.E.; DONE, H.J. Urease assay and ammonia release from tissue. Phytochemistry, v.22, n.1, p.663-667, 1983.

JOY, M.;ALIBÉS, X.; MUNOZ, F. Chemical treatment of lignocellulosic residues with urea. Animal Feed Science and Technologic, v.38, n.3-4, p.319-333, 1992.

MARTINS, R.M.O. Composição química e degradabilidade in situ do feno de capim-coastcross tratado com amônia anidra ou uréia. Jaboticabal: Universidade Estadual Paulista, 1992. 45p. Monografia (Graduação em Zootecnia) - Universidade Estadual Paulista, 1992.

NASCIMENTO, J.M. Efeitos da amonização sobre a ocorrência de fungos e composição química de fenos de Cynodon dactylon (L.) Pers. Jaboticabal: Universidade Estadual Paulista, 1994. 46p. Monografia (Graduação em Zootecnia) - Universidade Estadual Paulista, 1994.

OJI, U.I.; MOWAT, D.N.; WINCH, J.E. Alkali treatments of corn stover to increase nutritive value. Journal of Animal Science, v.44, n.5, p.798-802. 1977.

PEREIRA, J.R.A; ROSSI JR., P.P. Manual de avaliação nutricional de alimentos. Piracicaba: Fundação de Estudos Agrários Luiz de Queiroz, 1994. 34p.

REIS, R.A.; GARCIA, R.; SILVA, D.J. et al. Efeito da aplicação de amônia anidra sobre a composição química e digestibilidade de in vitro de fenos de três gramíneas tropicais. Revista da Sociedade Brasileira de Zootecnia, v.19, n.3, p.219-224, 1990.

REIS, R.A.; RODRIGUES, L.R.A.; NAHAS, H. et al. Amonização do feno de Brachiaria decumbens com diferentes níveis de umidade. Pesquisa Agropecuária Brasileira, v.28, n.4, p.539-543, 1993.

REIS, R.A.; RODRIGUES, L.R.A.; RESENDE, K.T. et al. Avaliação de fontes de amônia para o tratamento de fenos de gramíneas tropicais: 2. Compostos nitrogenados. Revista Brasileira de Zootecnia, v.30, n.3, p.682-686, 2001.

ROSA, B.; REIS, R.A; RESENDE, K.T. et al. Valor nutritivo dos fenos de Brachiaria decumbens Stapf cv. Basilisk submetido a tratamento com amônia anidra ou uréia. Revista Brasileira de Zootecnia, v.27, n.4, p.815-822, 1998. 
SAENGER, P.F.; LEMENAGER, R.P.; HENDRIX, K.S. Effects of anhydrous ammonia treatment of wheat straw upon in vitro digestion, performance and intake by beef cattle. Journal of Animal Science, v.56, n.1, p.15-20, 1983.

SAHNOUNE, S.; BESLE, J.M.; CHENOST, M. et al. Treatment of straw with urea. 1. Ureolysis in a low water medium. Animal Feed Science and Technology, v.34, n.12, p.75-93, 1991.

SCHMIDT, P.; WECHSLER, F.S.; VARGAS JR., F.M.; ROSSI, P. Valor nutritivo do feno de Braquiária amonizado com uréia ou inoculado com Pleurotus ostreatus. Revista Brasileira de Zootecnia, v.32, n.6, p.2040-2049, 2003 (Supl. 2).
SILVA, D.J.; QUEIROZ, A.C. Análise de alimentos: métodos químicos e biológicos. 3.ed. Viçosa, MG: Universidade Federal de Viçosa, 2002. 235p.

WILLIAMS, P.E.V., INNES, G.M., BREWER, A. Ammonia treatment of straw via the hidrolysis of urea. II. Additions of soya bean (urease), sodium hydroxide and molasses; effects on the digestibility of urea-treated straw. Animal Feed Science and Technology, v.11, p.115-124, 1984.

Recebido em: 13/08/03

Aceito em: 23/12/04 